\title{
Factors Influencing the Choice of Product Promotion Strategies on Facebook: An Empirical Evidence of Small and Medium-Sized Enterprises in Tanzania
}

\author{
Salimu Abushiri Jinyevu ${ }^{1 *} \quad$ Cheng Yanxia $^{1} \quad$ Jacob Julius Rombo $^{1} \quad$ Jamila Rashid Ng'itu $^{2}$ \\ 1.School of Management, Wuhan University of Technology, Wuhan, P.R. China,430070 \\ 2.School of Management, Shandong University, Jinan, P.R China
}

\begin{abstract}
The study focuses on examining factors which influence the selection of promotion strategies on Facebook among small and medium-size enterprises (SMEs) in Tanzania. The paper asses the influence of promotion objective, content and Facebook user on the selection of promotion strategies on Facebook. Also, it examines the influence of promotion strategies on Facebook. Since many past studies focus on consumer perspective, this study based on SMEs perspective which makes it the only one in Tanzania context as per researcher's knowledge. The primary data of the study were collected through self-monitored questionnaire from 259 respondents among 24 SMEs in urban Tanzania mainland. The secondary data were obtained from literature such as journals, books and websites. Interview and observation were used to enrich data collection. The study data were analyzed using SPSS software version 22 and SmartPLS 3.0. The structure equation modeling (SEM) used to find the relationships between the study constructs. The study results show that content, Facebook users, and promotion objectives have high positive significant influence on promotion strategies while content shows high significant positive influence on Facebook users. Moreover, promotion strategies found to have high positive significant influence on the selection of Facebook as a social network to carry out product promotion campaign. All study hypotheses supported. The study recommends proper selection of promotion strategies by considering the determinants factors discussed in the study for successful product promotion on Facebook. Also future research direction was recommended.
\end{abstract}

Keywords: Content, promotion objectives, promotion strategies, Facebook users, Facebook

DOI: $10.7176 / \mathrm{EJBM} / 11-30-03$

Publication date:October $31^{\text {st }} 2019$

\section{Introduction}

The emergence and mushrooming of social media brought new marketing opportunities and revolutionize the way marketing is done (Mangold \& Faulds, 2010). Social networking such as Facebook is a form of social media (Basher, et al 2012) which give opportunities to its users to construct their profile within bounded system share with one another, traverse their list of connections and those made by other users (Bays \& Ellison, 2017). Facebook is the leading social networking site used by many small and medium-sized enterprises (SMEs) in the world and Tanzania specifically to promote their products to users. In order for SMEs to promote their products on Social media, they must select effective promotion strategies. Choosing the best promotion strategy is a great challenge to many SMEs hence many marketing managers lacks the knowledge of strategies to apply on social media and hence missing many opportunities (Cox, 2012). Research on social media promotion strategy is a field of interest which grow rapidly but lacks effective framework to analyze and compare social media promotion strategies (Effing \& Spil, 2016)

Promotion strategy is a planning process which is a goal-driven in order to create user generated content under a vehicle of a group of internet applications for the purpose of creating a unique and valuable competitive position (Effing \& Spil, 2016)

This study takes the SME perspective since many past studies focuses on consumer perspectives. As per researcher's knowledge, there is no other past studies based on Tanzania context with similar subject matter and perspective, hence create a literature gap that this study tries to fill in, therefore this study will enhance understandings on right selection criteria of promotion strategies on Facebook and other social media by considering SMEs perspective

The study variables include content, promotion objectives, Facebook users, promotion strategies and Facebook

\section{Review of Literature and Hypothesis Formulation}

\subsection{The Influence of Content on Facebook Users}

Content and social media are inseparable, their relationship is symbolic (Daoud,2016). The content created and shared by small and medium-sized enterprises on social network such as Facebook, can be assessed using several dimensions namely the type of content and content activities. Content type refers to characteristics of the promotion campaign message on social networking such as Facebook in this regard. It includes the form of the content such 
as text, picture and video. According to Schreiner et al (2019) argue that video format of promotion campaign gets more engagement when posted on social media than other forms of content such as text only or picture. The topic of promotion campaign content also affects user engagement (Kuang, et al., 2016), such content like entertainment funny and humor content get high engagement. Content activities such frequency of posting the content, time of posting and the period of posting also affects engagements of users ((Kuang, et al., 2016). Also content influence social media users to click on the ads such as sponsored ads on social media (Mao and Zhang, 2015). Therefore, this study hypothesizes that;

$\mathrm{H} 1=$ Facebook users are significantly influenced by type of content.

\subsection{The Influence of Content on Promotion Strategy}

Different product promoters on social media have to focus on different promotion strategies based on content and context. The topic-interest has strong influence on promotion effectiveness. Moreover, target message when well personalized based on user interest have strong influence on effectiveness of the promotion (Kuang et al, 2016). On the other hand, as the content influence the users of social networks such as Facebook to engage with content, SMEs have to choose the best strategy that will influence that engagement. Any type of strategy applied on social network such as Facebook should match the type of content as well as go hand in hand with content activities in order to bring the effects expected. The content of promotion campaign can persuade users to buy a product or engage with the content only when the strategy used to create and share the content is right and effective. Therefore, the type of content dictate the strategy type to be applied in order to effectively affects users and persuade them to engage with the content or buy the product. The use of content strategies such as sponsored content strategy (Also called sponsored ads) depends much on the type of content. In sponsored content strategy, the length of content, the form of the content and the frequency to reach the users matters in affecting and persuading the users who see the ads content ( Jinyevu et al, 2018, Mao and Zhang, 2015., Kuang, et al, 2016,). This study therefore posits that; $\mathrm{H} 2$ : Promotion strategy is significantly influence by the type of content.

\subsection{The Influence of Facebook Users on Promotion Strategy}

The main focus for SMES is to reach their target audience on particular social media platforms. With reference to Facebook, the SMEs strategies on product promotion focus on the Facebook users. The Facebook users are the SMEs' target audience. In order to apply the right and effective strategy, the Facebook user characteristics must be considered. Naveed (2013) analyzed the audience measurement based on the audience size as well as characteristics such as direct consumers, retailers, end user products, trade dealers, customers by direct response, product or service users. Klososky (2011) argues that depending on the strategy that a company is planning to use, the volume of the audience using a particular social network is very crucial and should be taken into consideration. Jinyevu et al (2018) elaborates that promotion strategies specifically consumer endorser strategy affects the behaviour of young consumers in social media. This study therefore hypothesizes that;

H3: Promotional strategy is significantly influenced by Facebook users

\subsection{The Influence of Promotion Objectives on Promotion Strategies}

Any campaign carried out by SMEs on social media aim at specific objectives to be achieved such as driving traffics to website, product/brand awareness, boosting sales, encourage feedback from customers etc. Objectives need to follow the SMART approach meaning that they must be specific, measurable, attainable/achievable, realistic and time bound (Daoud, 2016). To achieve the objectives, right promotion strategies should be chosen. It should be noted that not any strategy can fit every objective, therefore strategy have to be selected in line with the objective it is expected to achieve. In encouraging engagement, the engagement strategies such as video contest and consumer endorser are more appropriate while in discount and gift on purchase strategy are more appropriate in achieving sales increase. Moreover, the use of celebrity endorsement strategy is more appropriate when achieving product or brand awareness objectives, persuading new consumers as well as achieving product/brand awareness (Jinyevu et al, 2018). The study posits that:

H4: Promotion strategy is significantly influenced by promotion objectives

\subsection{The Influence of Promotion Strategy on Facebook}

When SMEs plan for strategy to use, they must consider where the strategy is going to be used (Jinyevu, et al, 2018). With reference to Facebook, the SMEs have to take consideration of Facebook Characteristics when planning for the promotion campaign strategy to use. For example, using content strategies for promotion on Facebook, both the content characteristics have to match with Facebook characteristics in order for the strategy to be effective and successful. Facebook characteristics include the technical tools composition which are compatible with the strategy used. Example when using content strategy, does the format of the content is compatible with the Facebook structure? Is the type of content match with the characteristics of Facebook users? On the other hand, when using celebrity endorser as a strategy to promote product on social network, the SMEs have to take into 
consideration which social network does the celebrity has more influence and to what extent that social network will reach the target audience of the SMEs. Furthermore, when sponsored content/ads strategy is used by SMEs, it considers the social network with high number of users. Therefore, this study hypothesizes that; $\mathrm{H} 5$; The choice of Facebook is significantly influenced by promotion strategy to be chosen

\section{Conceptual Model}

The conceptual model derived from the review of literature. The model shows the relationship between the study construct. It describes influencing factors for the choice of promotion strategies and the choice of Facebook as a social media channel for product promotion.

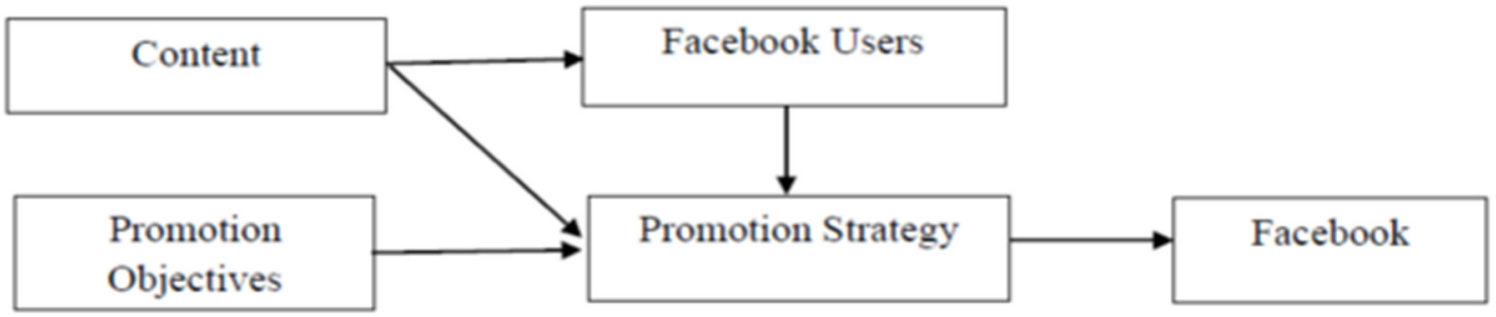

Figure 2: Conceptual Model

\section{Methodology}

4.1 Data Collection

This study employs primary and secondary data. Secondary data were collected from previous studies from different journals, books, and other related literature. Primary data were collected from self-monitored questionnaire, interview and observation. Questionnaires were distributed through online channels by sharing links to particular respondents. The main methodology used is structure equation modeling.

\subsection{Population and Sample Selection}

This study uses the SMEs perspectives and hence the sample population is from SMEs staffs and Managers/leaders especially form the marketing department in Tanzania mainland. The sample selected from urban SMEs because they are mostly users of social media than in rural areas due to internet infrastructures challenges in rural areas.

\subsection{Data Analysis Techniques}

Study data were analyzed using Structure equation modeling (SemPLS3.0) and SPSS statistics software version 22. Different data analysis techniques were used such as Chronbach's Alpha for reliability Test. Moreover, regression analysis was also performed. Lastly, Descriptive data analysis was conducted to compute frequency and percentage.

\section{Findings and Discussion}

\subsection{Sample Composition}

300 questionnaires were distributed among SMEs marketing staffs and Marketing managers, 259 were filled in and collected back accounts for $86.3 \%$. There is no missing data found in the descriptive analysis performed as it shows $\mathrm{N}=259$ for all items in the questionnaire. Demographic details of respondents were analyzed based on gender, marital status, position and education level of respondents. The demographic details were summarized in table 1 below 
Table 1 Demographic Result of Respondents

\begin{tabular}{|c|l|l|}
\hline Characteristics & Frequency (f) & Percentage (\%) \\
\hline Gender: A) Male & 180 & 69.5 \\
B) Female & 79 & 30.5 \\
Total & 259 & 100.0 \\
\hline Level of education A) Undergraduate & 177 & 68.3 \\
B) postgraduate & 47 & 18.1 \\
C)Non-degree & 35 & 13.5 \\
Total & 259 & 100.0 \\
\hline B) Married & 183 & 70.7 \\
Total Single & 76 & 29.3 \\
B) Leader/Manager & 259 & 100.0 \\
Total & 195 & 75.3 \\
\hline Position: A) Marketing dept. staffs & 164 & 24.7 \\
\hline
\end{tabular}

\subsection{Evaluation of the Model Measurements}

The model measurements explain the relationship between observed variable and the latent variables. In order to measure the model, validity and reliability are used. Also a confirmatory factor analysis was applied in this study as a widely used method to examine the probable underlying factor structure of a set of observed variables without impressing a preconceived structure on the results (Child, 1990, Treiblomaire and Filzmoserm 2010 in Mkonya, 2018)

\subsubsection{Validity Measurement}

\subsubsection{Construct Validity}

Construct validity and descriptive validity was performed in order to estimate the validity of the construct. Average variance Extracted (AVE) was used to show an average amount of variation that a latent variable is able to explain in the observed variable to which theoretically associate with (Farrel, 2009). Construct validity is regarded as sufficient when AVE of a construct is higher than 0.5 (Fornell and Larcker, 1981) which means the construct shows more than $50 \%$ of the variance within the scale indicator (Hier et al, 2012). This study uses smartPLS to measure the value of average variance extracted. Table 2 indicates construct validity which asses the measurement model. It shows that the value of construct loading for all variables are all greater than 0.5 and hence are within the acceptable range.

\begin{tabular}{|l|l|l|l|l|}
\hline \multicolumn{2}{|c|}{ Table 2: Construct Validity } \\
& $\begin{array}{l}\text { Cronbach's } \\
\text { Alpha }\end{array}$ & $\begin{array}{l}\text { rho_ } \\
\text { A }\end{array}$ & $\begin{array}{l}\text { Composite } \\
\text { Reliability }\end{array}$ & $\begin{array}{l}\text { Average Variance Extracted } \\
\text { (AVE) }\end{array}$ \\
\hline Content (CT) & $\mathbf{0 . 8 5 9}$ & $\mathbf{0 . 8 6 0}$ & $\mathbf{0 . 9 0 4}$ & $\mathbf{0 . 7 0 2}$ \\
\hline Facebook (F) & $\mathbf{0 . 8 5 8}$ & $\mathbf{0 . 8 6 4}$ & $\mathbf{0 . 9 1 3}$ & $\mathbf{0 . 7 7 8}$ \\
\hline Facebook Users (FBU) & $\mathbf{0 . 7 9 1}$ & $\mathbf{0 . 7 9 8}$ & $\mathbf{0 . 8 7 8}$ & $\mathbf{0 . 7 0 7}$ \\
\hline $\begin{array}{l}\text { Promotion } \\
\text { Objective(POB) }\end{array}$ & $\mathbf{0 . 8 1 6}$ & $\mathbf{0 . 8 1 6}$ & $\mathbf{0 . 8 9 1}$ & $\mathbf{0 . 7 3 2}$ \\
\hline $\begin{array}{l}\text { Promotion Strategy } \\
\text { (PS) }\end{array}$ & $\mathbf{0 . 8 6 3}$ & $\mathbf{0 . 8 6 7}$ & $\mathbf{0 . 9 0 1}$ & $\mathbf{0 . 6 4 7}$ \\
\hline
\end{tabular}

5.2.1.2 Discriminative Validity

Using smartPLS, the study conducted discriminative validity using Forner and Lacker (1981) Criteria through comparative analysis of the square roots of average variance extracted (AVE) in each construct with correlation between other constructs. Table 3 shows a diagonal value which shows the square root of average variance and the correlation among the other constructs in off-diagonal style. The findings of the study show that the square root of average variance extracted from each construct is greater than the correlation between other construct hence support the discriminative validity 
Table 3: Discriminative Validity

\begin{tabular}{|l|l|l|l|l|l|}
\hline Constructs & $\begin{array}{l}\text { Content( } \\
\text { CT) }\end{array}$ & $\begin{array}{l}\text { Facebook } \\
\text { (FB) }\end{array}$ & $\begin{array}{l}\text { Facebook Users } \\
\text { (FBU) }\end{array}$ & $\begin{array}{l}\text { Promotion } \\
\text { Objective (POB) }\end{array}$ & $\begin{array}{l}\text { Promotion } \\
\text { Strategy (PS) }\end{array}$ \\
\hline Content (CT) & $\mathbf{0 . 8 3 8}$ & & & & \\
\hline Facebook (FB) & 0.713 & $\mathbf{0 . 8 8 2}$ & & & \\
\hline $\begin{array}{l}\text { Facebook Users } \\
\text { (FBU) }\end{array}$ & 0.696 & 0.654 & $\mathbf{0 . 8 4 1}$ & $\mathbf{0 . 8 5 5}$ & \\
\hline $\begin{array}{l}\text { Promotion } \\
\text { Objective (POB) }\end{array}$ & 0.854 & 0.733 & 0.686 & 0.786 & $\mathbf{0 . 8 0 4}$ \\
\hline $\begin{array}{l}\text { Promotion } \\
\text { Strategy(PS) }\end{array}$ & 0.776 & 0.852 & 0.719 & & \\
\hline
\end{tabular}

5.2.2 Reliability Test

Reliability was computed in order examine the stability as well as consistency of the scale in measuring concepts. The most widely used test to measure internal consistency is by calculating Cronbach's Alpha which describe the coefficient of inter-item correlation. The consistency of coefficient ranges between 0 and 1 , however when the value is higher, shows higher consistence (Cohen et al. 2007). The study by Haier et al (2012) explain that when the value of Cronbach's Alpha is higher than 0.70 it is assumed as suitable internal consistency while 0.6 and 0.70 is assumed as reasonable. On another perspective, Nunally and Bernstein (1994) assume that there is no reliability if Cronbach's Alpha value is less than 0.60. Table 2 indicates the Cronbach's Alpha value and the composite reliability. The findings of the study show that Cronbach's Alpha ranges between 0.791 and 0.863 which indicates very high and suitable internal consistency.

\subsection{Structure Equation Modeling (SEM)}

In order to find the relationships among the study construct, the structure model was applied. Endogenous and exogenous was used as suggested by Ringle and Sartedt (2011). To calculate the relationships, the PLS algorithm were used. The general PLS path model was used in order to identify the relationship between the research variables which is;

$$
L V j=\beta_{0}+\sum_{i \rightarrow j} \beta j i L V i+\operatorname{error} j
$$

$L V i$ : Denote all latent variables required to Predict $L V j$. Bji: Represent path coefficient which shows the strength and direction of the relations between the response $L V j$ and the predictors $L V i$. Also $\beta_{0}$ : This is an intercept term. Error $j$ : Present accounts for the residuals. In order to examine the relationship between variables, this study adopted the following PLS mathematical model.

$$
\mathrm{PS}=\mu_{0}+\mu_{1} \mathrm{CT}+\mu_{2} \mathrm{POB}+\mu_{3} \mathrm{FBU}+\text { error }
$$

$$
\mathrm{CT}=\gamma_{0}+\eta_{1} \mathrm{FBU}+\text { error }
$$

$$
\mathrm{FB}=\alpha_{0}+\alpha_{1} \text { PS }
$$

Notes: $\mathrm{CT}=$ Content, $\mathrm{PS}=$ Promotion Strategy, $\mathrm{POB}=$ Promotion objectives, $\mathrm{FB}=$ Facebook, $\mathrm{FBU}=$ Facebook users 5.3.1. The Goodness of Model Fit Evaluation

It was performed to validate a partial least square path model by evaluating overall prediction performance of the inner and outer model. According to Hensler, et al (2016) explain that Standardized Root Mean Score Residual (SRMR) is the most widely used and appropriate measure of the model fit while Haier, et al (2014) elaborate that SRMR value less than 0.1 is regarded as appropriate fit index. The study findings show that the value of Standardized Root Mean Score Residual (SRMR) is 0.061 for saturated model and 0.065 for estimated model

Table 4: Evaluation of the Goodness of Model Fit

\begin{tabular}{|l|l|l|}
\hline Fit Criteria & Saturated Model & Estimated Model \\
\hline SRMR & 0.061 & 0.065 \\
\hline
\end{tabular}

5.3.2 Evaluation of Coefficient of Determination ( $R$ square)

$\mathrm{R}^{2}$ is the main measurement used to evaluate the inner model (Haier et al, 2002). When $\mathrm{R}^{2}$ is around $0.67,0.33$ and 1.9 for endogenous latent variables of the inner model are regarded as substantial, moderate or week (Chin, 1998). 
Table 5: Results of $\mathrm{R}^{2}$ and Adjusted $\mathrm{R}^{2}$

\begin{tabular}{|l|l|l|}
\hline & R Square & R Square Adjusted \\
\hline Facebook (FB) & 0.726 & 0.725 \\
\hline Facebook Users (FBU) & 0.484 & 0.482 \\
\hline Promotion Strategy (PS) & 0.697 & 0.694 \\
\hline
\end{tabular}

Moreover, the study calculated the semPLS algorithm of structure model as shown in figure 2.

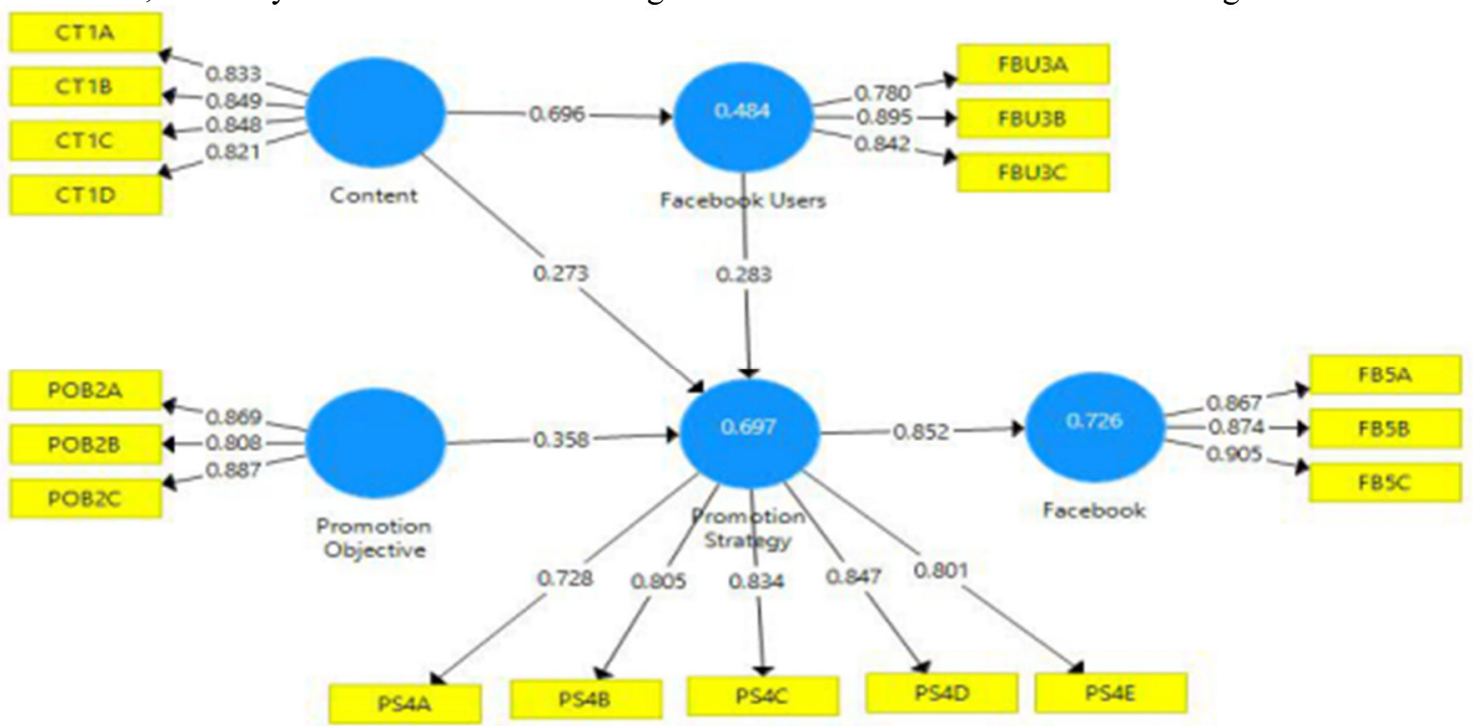

Figure 3: Figure 2: semPLS Algorithm Structure Model

The findings show that Facebook (FB) has $\mathrm{R}^{2}$ value of 0.726 which is substantial, Facebook Users (FBU) 0.484 which is moderate and Promotion strategy (PS) 0.697 which is substantial. This is interpreted that the variables specifically explain $72.6 \%$ an $69.7 \%$ of the variation in Facebook and Promotion strategy and $48.4 \%$ variation in Facebook users

\subsection{Hypothesis Testing}

It was analyzed through boot strapping results using semPLS 3.0. The ratio of each parameter was estimated at its standard error is distributed as t-statistics and it is significant at the level 0.05 when the t-statistics value is great than 1.96 and at the level of 0.01 when the t-statistics is greater than 2.58 , also at the level of 0.001 when the value is greater to 3.29. Table 6 shows a summary of study findings of the standard path coefficient as well as their significant value used in hypothesis testing. The study results show that all hypothesis supported.

Table 6 Path Coefficients

\begin{tabular}{|l|l|l|l|l|l|l|l|}
\hline Hypothesis & & $\begin{array}{l}\text { Original } \\
\text { Sample (O) }\end{array}$ & $\begin{array}{l}\text { Sample } \\
\text { Mean (M) }\end{array}$ & $\begin{array}{l}\text { Standard } \\
\text { Deviation } \\
(\text { STDEV) }\end{array}$ & $\begin{array}{l}\text { T Statistics } \\
(\mid \mathbf{O} / \text { STDEV|) }\end{array}$ & $\begin{array}{l}\text { P } \\
\text { Values }\end{array}$ & Decision \\
\hline H1 & CT-> FBU & 0.696 & 0.697 & 0.035 & 19.793 & 0.000 & Supported \\
\hline H2 & CT -> PS & 0.273 & 0.275 & 0.098 & 2.776 & 0.006 & Supported \\
\hline H3 & FBU -> PS & 0.283 & 0.280 & 0.062 & 4.552 & 0.000 & Supported \\
\hline H4 & POB-> PS & 0.358 & 0.360 & 0.084 & 4.241 & 0.000 & Supported \\
\hline H5 & PS -> FB & 0.852 & 0.854 & 0.016 & 52.030 & 0.000 & Supported \\
\hline
\end{tabular}

Notes: $\mathrm{CT}=$ Content, $\mathrm{POB}=$ Promotion Objectives, $\mathrm{PS}=$ Promotion Strategies, $\mathrm{FB}=$ Facebook, FBU=Facebook user. Moreover, the study calculated the semPLS bootstrapping of structure model as shown in figure 3. 


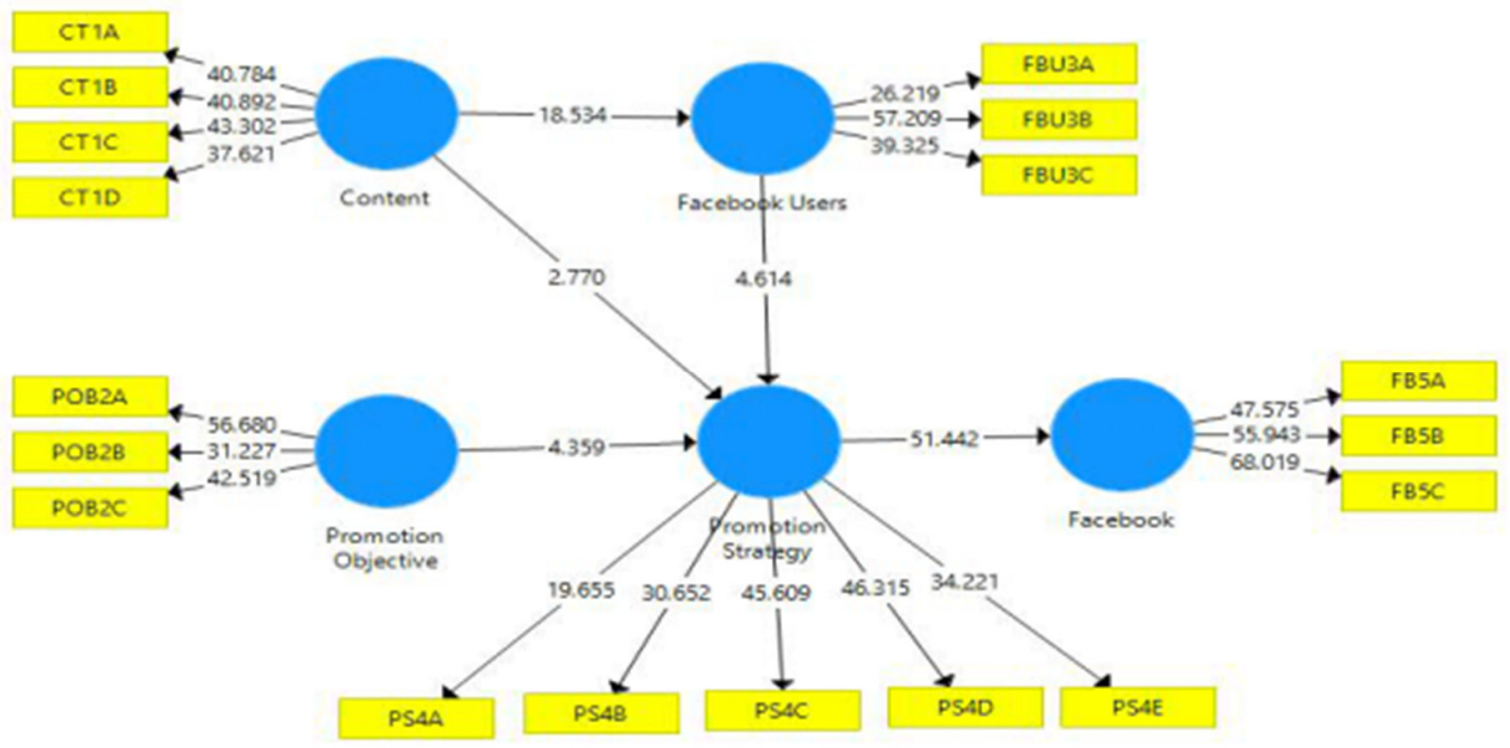

Figure 4:semPLS Bootstrapping of Structure Model

Notes: $\mathrm{CT}=$ Content, $\mathrm{POB}=$ Promotion Objectives, $\mathrm{PS}=$ Promotion Strategies, $\mathrm{FB}=$ Facebook, $\mathrm{FBU}=$ Facebook user 5.4.1 The Influence of Content on Facebook Users

The findings of study from table 6 show that content has a very high positive significant influence on Facebook users (t-value 19.793, $\mathrm{P}<0.001)$ therefore support $\mathrm{H} 1$. This finding also supports literature review from other past studies such as Mao and Zhang (2015), Daouud, (2016,) Naveed (2013). Therefore, content directly affects Facebook users. The topic of the content, the form of the content and content activities such as frequency of posting the content directly affects Facebook user behaviors such as engagement with the content through sharing of Facebook post, commenting or writing review of the product on Facebook or by clicking the like button on Facebook.

\subsubsection{The Influence of Content on Promotion Strategy}

The result of the study from table 6 show that content has high significant influence on promotion strategies (tvalue 2.776, $\mathrm{P}<0.01$ ) hence support H2. It is supported by literature (Naveed, 2013; Daoud, 2016, Kuang et al, 2016). This indicate that content determine what kind of strategy should be used by SMEs on Facebook in order to have effective and efficient promotion campaign. The topic of content such as entertainment topic, form content such as video, picture and text, length of content, time of posting and frequency of posting positively influence the selection of promotion strategy on Facebook. The promotion strategies selected must match the content characteristics.

\subsubsection{The Influence of Facebook users on Promotion Strategy}

The result of the study shows that Facebook users significantly influence the selection of promotion strategy on Facebook having a t-value 4.552, $\mathrm{P}<0.001$, hence support H3. This is also supported by literature (Jinyevu, 2018., Winer,2009). Facebook users serves as target audience of promotion campaign. The characteristics of Facebook users such as gender, education level, social and economic status have positive influence on the selection of promotion strategies by SMEs on Facebook. When SMEs plan their promotion strategies on Facebook such as Sponsored Ads strategy, video contest strategy, engagements strategies etc. must also consider the profile of target audience who are the Facebook users in order to insure the strategy fits right audience. Failure to consider the characteristics of Facebook users, may lead to improper selection of strategies.

5.4.4 The Influence of Promotion Objective on Promotion Strategy

The study finding shows that promotion objective has high positive significant influence on promotion strategies ( $\mathrm{t}-\mathrm{value} 4.241, \mathrm{P}<0.001$ ) hence support H4. Before running any promotion campaign on Facebook, objectives need to be stated clearly. Different objectives have different promotion strategies. It is the duty of SMEs to set clear objectives before selecting the type of promotion strategy. Objectives such as creating product awareness uses different promotion strategy compared with objectives such as boosting sales which also needs different strategy which will insure customers buy products and increase sales example of strategy which boost sales is like discount price and gift on purchase. Therefore, promotion objective dictates the kind of promotion strategy to be applied on Facebook.

5.4.5 The Influence of Promotion Strategy on Facebook

The result of the study indicates that promotion strategy has high positive significant influence on the choice of Facebook (t-value 52.030, $\mathrm{P}<0.001$ ) therefore support H5. Before SMEs select a promotion strategy it is important to consider where the strategy is going to be applied. The kind of strategy influence the choice of social network, 
that means the strategy must match the social network characteristics. Therefore, promotion strategy must match the characteristics of Facebook as a social network site. It should be noted that not all strategies match any social networks because each social network has different features. Hence promotion strategy on Facebook must match with the features of Facebook for an effective promotion strategy

\subsection{Managerial Implication}

This study finds out that content has high positive significance on Facebook users. It is the recommendation of this study to SMEs managers to professionally create content that positively impact Facebook users. The content should be created by considering the characteristics of Facebook users in order to effectively affect their online behavior so as to engage positively with the content and buy the product as well.

Proper selection of promotion strategy is the key for the promotion campaign to be effective and successful. The study recommends that SMEs managers to take into consideration the content, the characteristics of Facebook users and setting clear promotion objectives as important determinants for selection of effective promotion strategy on Facebook and other social networking sites.

Furthermore, the study results find out that promotion strategy has high significant positive influence on selection of Facebook as a platform to carry out promotion campaign. Therefore, SMEs managers should consider promotion strategies as an important determinant when selecting a social media platform for promotion campaign. The study recommends that SMEs managers to assess their promotion strategies before applying them to the social network sites of their choice and should bear in mind that the right strategy is the one that matches the features of social network sites selected.

\section{Conclusion}

This study focuses on examining factors influence the choice of promotion strategies on Facebook. The results show that content, promotion objectives and Facebook users have high significant positive influence on the choice of promotion strategies on Facebook. Moreover, content has high significant influence on Facebook users. Furthermore, promotion strategies show high significant influence on the selection of Facebook. All study hypotheses supported. The study is limited to Facebook and by considering SMEs perspective only The study only asses the influence of few selected factors, it is the recommendation of this study that future research can be done with a much wider sample which include more factors and more social networking sites.

\section{References}

Belch, G. Belch, M. (209) “Advertising and Promotion: An Integrated Marketing Communications Perspective” . New York: McGraw-Hill International Edition.

Claire Mercer, (2006) ."Telecentres and transformations: modernizing Tanzania through the Internet", African Affairs, 105, 243-264.

Constantine, D. (2013), "The social media and organization performance among civil society Organization in Tanzania." Dissertation for Award of M.A Degree at University of Dar-es-salaam: Tanzania, 73.

Cox, S, (2012) "Social Media Marketing in a Small Business: A Case Study". Department of Computer Graphics Technology Degree Thesis. Paper

Daoud, H (2016), "8 Essential Elements of Social media marketing strategy”. [Online]

Effing, R \& Spil, T.A.M. (2016) "The social strategy cone: Towards a framework for evaluating social media strategies.". International journal of information management, Volume 36, Issues 1,1-8

Field, A.P. (2009). Discovering statistics using SPSS: and sex and drugs and rock' $n$ "roll. $3^{\text {rd }}$ Edition, London: Sage.

Fornell, C. and Larcker, D.F. (1981) "Evaluating Structural Equation Models with unobservable Variables and Measurement Error". Journal of Marketing Research, 18, 39-50.

Haier, J, Ringle, C, and Sarstedt, M (2011) "PLS-SEM: Indeed, a silver Bullet". Journal of marketing theory and practice, 19(2), 139-151

Hair, J.F., Sarstedt M, Pieper T.M., and Ringle C.M. (2012) "The use of partial list squares structure equation modeling in strategic management research: A review of past practices and recommendations for future applications "Long range Planning, 45(5), 320-340

Hair, J.R, J.F, Black, W.C., Babin, B.J., Anderson, R.E. and Tatham, R.L. (2006) "Multivariate Data Analysis". 6th Ed., Pearson-Prentice Hall, Upper Saddle River, NJ,

Jinyevu, S.A., Mkonya,V.L., Dantur, M.L (2018) "Exploring the use of consumer endorser strategy in social media product promotion advertisement and its impacts on young consumers behavior in Tanzania". Proceedings of the 15th international conference on innovation and management, Wuhan University of Technology press, 2, 764-770

Klososky, S. (2011).” Manager's guide to social media”. New York, The McGraw-Hill Companies.

Kuang,K, Jiang,M, Cui, P and Yang,S.(2016). "Steering Social Media Promotions with Effective Strategies", 2016 
IEEE 16th International Conference on Data Mining (ICDM), Barcelona, 985-990

Mangold, W. G., \& Faulds, D.J. (2009). "Social media: the new hybrid element of the promotion mix." Business Horizons, 62(4), 357-365.

Mao, E., Zhang ,J. (2015) "What drives consumers to click on social media Ads?. The role of content, media and individual factor. " 2015 48th Hawaii international conference on system science, 3405-3413

Mkonya, V.L. (2018) "The Impact of accounting information system on quality report and project sustainability of non-governmental organization in Tanzania", PhD Dissertation, Wuhan University of Technology. China

Naveed, K (2013), "Factors influencing the media selection" [Online]. Available: https://www.masscommunicationtalk.com/factors-influencing-the-media-selection.html (August 9, 2019)

Paquette, H. (2013), "Social media as a marketing Tool: A literature Review". Major papers by Master of Science Studies. Paper 2.

Parker, C. (-) "301 Ways to use social media to boost your marketing”. McGraw-Hill

Ringle, C. M., Wende, S., and Becker, J.-M. 2015. "SmartPLS 3." Boenningstedt: SmartPLS GmbH, http://www.smartpls.com

Saunders, M., Lewis, P and Thornhill, (2009), "A research method for Business students". Pearson Education Limited, Essex

Schreiner, M., Fischer., Riedl, R. (2019) "Impact of Content Characteristics and emotion on behavioral engagement in social media: literature review and research agenda", Electronic commerce research.

Scott, D. M. (2009). "The new rules of marketing and PR: how to use social media, blogs, news releases, online video, and viral marketing to reach buyers directly". Wiley.com.

Spence, A. (2013) "Facebook Marketing the Ultimate Guide." [Online]

Treem, J., \& Leonardi,P (2012) "Social media use in organizations: Exploring the affordances of visibility, editability, persistence, and association." Communication Yearbook, 36, 143-189.

Wilson, R.E., Gosling, S.D., Graham, L.T., (2012) “A review of Facebook research in the social sciences.” Persp. Psychol. Sci, 7 (3), 203-220. 